\title{
Daubaylia belicopbilus n. sp. (Daubayliidae: Nematoda) a parasite of the snail, Gyraulus spirillus from Taiwan
}

\author{
par G.-O. POINAR, Jr (*) and Ch. S. RICHARDS \\ I.N.R.A. - Station de Recherches sur les Nématodes 123, boulevard du Cap, Antibes 06600 \\ Laboratory of Parasitic Diseases, National Institutes of Health Bethesda, Maryland, U.S.A.
}

\section{Summary.}

The nematode, Daubaylia helicophilus sp. n., is described from the snail, Gyraulus spirillus, originating from Taiwan. This species is distinguished from previously described members of the genus by the shape of the tail in both sexes, as well as the overall length and size and shape of the spicules and gubernaculum, respectively.

Populations of infected snails have been maintained for a period of years and ingestion of the gravid female nematode seems to be at least one mode of infection. D. helicophilus will also infect other snails, experimentally, including the schistosome-bearing snail, Biomphalaria glabrata.

\section{Résumẹé.}

Le nématode, Daubaylia helicophilus sp. n., est déerit à partir d'un planorbe, Gyraulus spirillus, originaire de Taïwan.

Cette espèce se distingue des autres espèces voisines du genre par la forme de la queue des deux sexes, mais aussi par la longueur totale du corps et la forme et la longueur des spicules et du gubernaculum.

Des populations de mollusques contaminés ont été maintenues pendant plusieurs années et au moins l'un des modes d'infestation semble être l'ingestion de la femelle gravide du nématode. Expérimentalement $D$. helicophilus peut aussi infester d'autres planorbes dont Biomphalaria glabrata, agent vecteur du schistosome.

Accepté le 21 juin 1979.

(*) On leave from the Department of Entomology and Parasitology, University of California, Berkeley 


\section{Introduction}

Members of the genus Daubaylia are unique in their apparently obligatory role as parasites of snails. Previous reports describe these nematodes as parasites of Gyraulus, Helisoma and Planorbis snails and D. potomaca Chit. and Chit. was shown to be transmissible to Biomphalaria glabrata, thus presenting a possible biological control agent of snail vectors of human disease (Chernin et al., 1960).

The present report describes a new species of Daubaylia that was originally received from Taiwan snails of Gyraulus spirillus.

\section{Matérials and methods}

Specimens of Gyraulus spirillus (Gould) received from Taiwan in 1967 were maintained in the laboratory in $400 \mathrm{ml}$ beakers with Romaine lettuce as a food source. Parasite transmission was continued by placing healthy snails in with the infected snails one or twice each year. Nematodes for taxonomic study were removed from the hemocoel of infected $G$. spirillus, killed in heated saline $\left(80^{\circ} \mathrm{C}\right)$, fixed in $3 \%$ formalin and processed to glycerin with the simple evaporation method described by Poinar (1975).

\section{Results}

The nematodes removed from G. spirillus were discovered to represent a new species of Daubaylia and are described below. In the quantitative portion of the description, all measurements are given in microns unless otherwise specified. The number following the character is the average value and the figures in parentheses represent the range of that character.

\section{Description.}

Daubayliidae (Chitwood and Chitwood) Poinar, 1978; Rhabditoidea (Oerley) Travassos; Rhabditida (Oerley) Chitwood.

This family was originally designated as a subfamily of the Cephalobidae (Chitwood and Chitwood, 1934) and later raised to family rank (Poinar, 1977). It is redefined here. Relatively slender nematodes with a smooth cuticule; six lips either partially or completely fused; amphids dorsolateral; stoma greatly reduced, lacking a glottoid apparatus; pharynx elongate, composed of a slender cylindrical muscular corpus leading into an elongate isthmus that in turn gradually expands into a glandular basal bulb lacking a valve; ovary single, reflexed; testis single, reflexed; spicules paired, separate, gubernaculum present; bursa present. The family contains the single genus Daubaylia. 


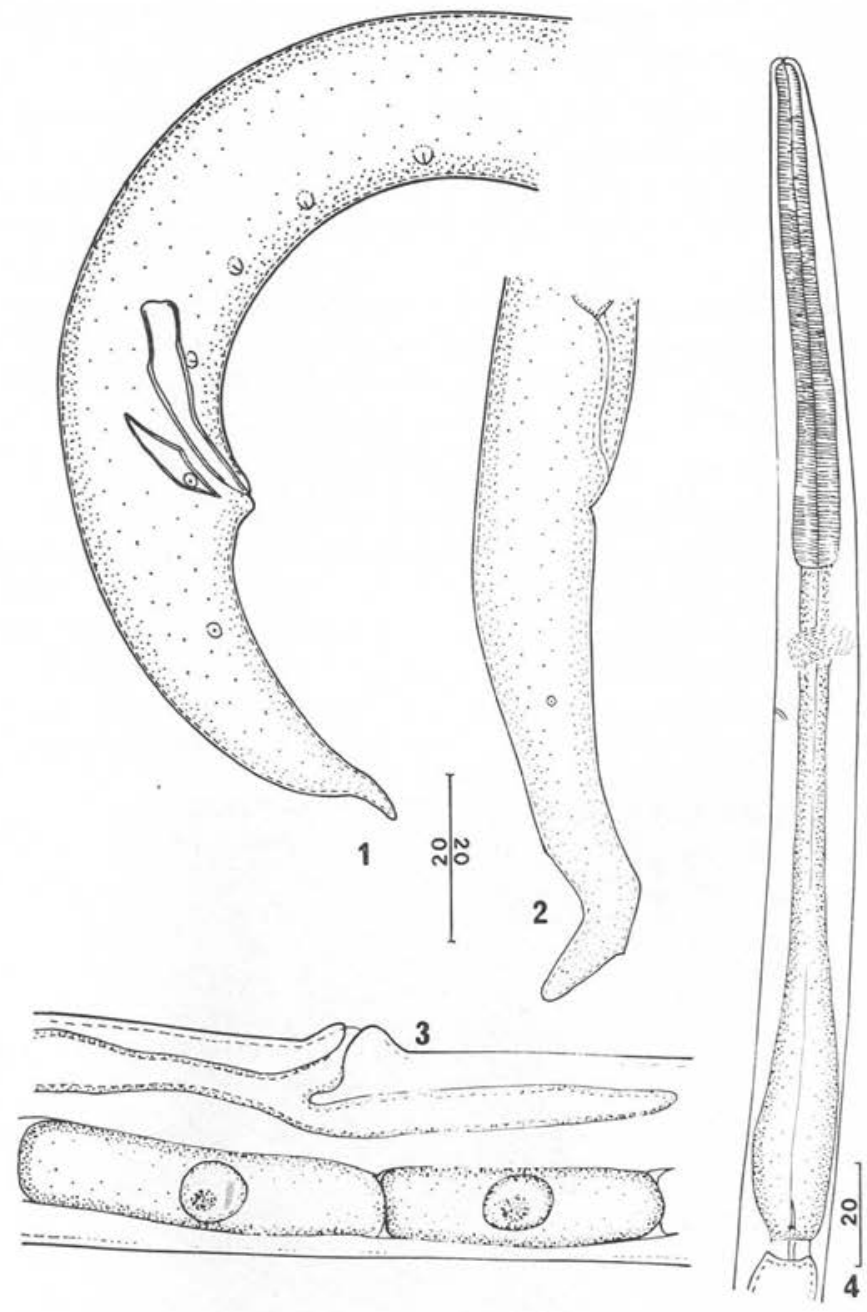

Fig. 1-4. Daubaylia helicophilus sp. n. I. Lateral view of male tail. 2. Lateral view of female tail. 3. Lateral view of vulva. 4. Lateral view of female pharynx. All values are in microns.

Daubaylia helicophilus n. sp. (fig. 1-5). With characters as presented in the family description; lips fused; amphids indistinct; stoma reduced, narrow; nerve ring circles isthmus portion of pharynx just below junction with the cylindrical corpus; excretory pore opens slightly below the level of the nerve ring; vulva projecting slightly; postuterine sac generally longer than body width at vulva; female tail with a notch behind the anus; tip of female tail bent dorsally, usually at an angle of $70-90^{\circ}$ in relation to the body axis; male tail tip either straight or bent ventrally, but never more than $90^{\circ}$; spicules separate; guberna- 
culum boat shaped; tail with six pairs of genital papillae arranged in two ventro-lateral rows; four pairs are preanal, one pair adanal and one pair postanal.

Female $(\mathrm{N}=10)$. Length, $1.27(1.11-1.36) \mathrm{mm}$; greatest width, $21(16-25)$; distance from head to nerve ring, 118 (100-130); distance from həad to excretory pore, 127 (113-138); length of pharynx, 200 (190-245); length of tail, 67 (60-80); distance ovary is reflexed behind the vulva, 152 (80-220); \% vulva, 61 (57-63); length of postvulvar sac, 34 (35-36); length of eggs, 60; width of eggs, 22-24.

MALE $(\mathrm{N}=2)$. Length, $1.0(0.97-1.05) \mathrm{mm}$; greatest width, 22 (20-24); distance from head to nerve ring, 100 (95-105); distance from head to excretory pore, 116 (113-120); length of pharynx, 170 (165-175); length of tail, 37 (35-4)); length of spicules, 24 (23-25); length of gubernaculum, 15 (14-16).

TYPE LOCALITY : Taiwan.

TYPE HOST : Gyraulus spirillus (Gould) Planorbidae : Mollusca.

TYPE SPECIMENS : Holotype (female) and male (allotype) deposited in the nematology collection at the Muséum National d'Histoire Naturelle, Paris.

Diagnosis : The straight tail on the female of D. helicophilus separates this species from D. seistanensis Baylis and Daubney that was described from Gyraulus convexiusculus in Persea. The male of the latter species also has a narrow rather than a broad gubernaculum and a different pattern of genital papillae. D. potomaca Chit and Chit. is a larger nematode than D. helicophilus and the tip

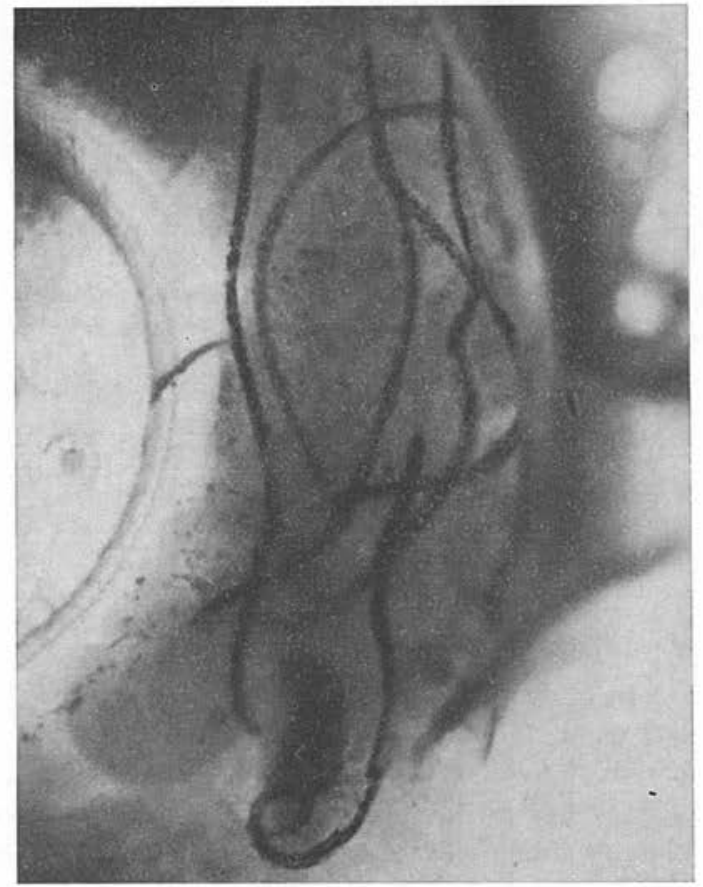

Fig. 5. Adults of Daubaylia helic sphilus sp. n., in the həmocoel of Gyraulus spirillus (mag. $\times 100$ ). 
of the female tail is bent 180 degrees, similar to D. deiviti Schuurmans Stekhoven. D. elegans is a much larger nematode that possesses smaller spicules and a narrower gubernaculum than the present species.

Recently, Dr John T. Sullivan sent the present authors a manuscript describing a Daubaylia malayanum from Malaysia. However, the male tail is bent $180^{\circ}$ in relation to the axis of the body and the female tail is straight and not bent dorsally at $90^{\circ}$ as with D. helicophilus.

BIOLOGICAL OBSERVATIONS : Parasite transmission was achieved over a 10 year period by adding uninfected snails to beakers containing infected individuals once or twice a year. Infection can be initiated by gravid female nematodes which leave their hosts while the latter are still living. After ingestion by another snail, the nematodes pass down the intestine and enter the hemocoel. Populations of nematodes appear as dark strands inside the snail ( fig. 5) due to their red color from ingestion of host hemolymph. The females multiply inside their host host and eventually kill the snails.

Aside from its normal host, gravid females of $D$. helicophilus are able to enter the hemocoel of the snails, Drepanotrema simmonsi, Biomphalaria straminea, B. obstructa and the schistosomebearing snail, $B$. glabrata, however reproduction has not been observed in these hosts. More studies are necessary to determine if this lack of reproduction is due to host immunity or other factors. If the latter is the case, then detailed studies on the life history of this nematode would be warrented, in relation to its potential use as a biological control agent of snails.

\section{References}

1. Chernin E., Mickelson E. H., Augustine D. L., 1960 : Daubaylia potomaca, a nematode parasite of Helisoma trivolvis transmissible to Australorbis glabratus, J. Parasitol., 46, 599-607.

2. Chitwood B. G., Chitwood M. B., 1934 : Daubaylia potomaca n. sp., a nematode parasite of snails, with a note on other nemas associated with molluscs. Proc. Hel. Soc. Wash., 1, 8-9.

3. Poinar, Jr, G. O., 1975 : Entomogenous nematodes. E. J. Brill, Publ. Leiden, 317.

4. Poinar Jr, G. O., 1977 : CIH key to the groups and genera of nematode parasites of invertebrates. Commonwealth Agricultural Bureaux, Farnham Royal, Bucks, 43 p. 